\title{
Understanding the seismic velocity structure of Campi Flegrei caldera (Italy): from the laboratory to the field scale
}

S. Vinciguerra ${ }^{1}$, C. Trovato ${ }^{1,2}$, P.G. Meredith ${ }^{3}$, P.M. Benson ${ }^{3}$, G. De Luca ${ }^{4}$, C.

Troise $^{1}$, G. De Natale ${ }^{1}$

${ }^{1}$ Osservatorio Vesuviano - Istituto Nazionale di Geofisica e Vulcanologia, Via

Diocleziano 328, 80124, Naples, Italy

${ }^{2}$ D’Appolonia spa, Via San Pasquale Chiaia 62, 80121, Naples, Italy

${ }^{3}$ Department of Earth Sciences, University College London, Gower Street, London

WC1E6BT, London, United Kingdom

${ }^{4}$ Servizio Sismico Nazionale, Via Curtatone 3, 00185, Rome, Italy

\begin{abstract}
We report laboratory measurements of $\mathrm{P}$ and $\mathrm{S}$ wave velocities on samples of tuff from Campi Flegrei (Italy), and a new tomographic velocity map of the Campi Flegrei caldera. Laboratory measurements were made in a hydrostatic pressure vessel during both increasing and decreasing effective pressure cycles. Selected samples were also thermally stressed at temperatures up to $600^{\circ} \mathrm{C}$ to induce thermal crack damage. Acoustic emission output was recorded throughout each thermal stressing experiment, and velocities were measured after thermal stressing. P and $\mathrm{S}$ wave travel times from a set of 331 local earthquakes that occurred in the period 1970 to 1984 have been used to generate 3-D tomographic images of distributions of both $\mathrm{Vp}$ and the $\mathrm{Vp} / \mathrm{Vs}$ ratio using the inversion package SIMULPS13Q.

Laboratory $\mathrm{P}$ and $\mathrm{S}$ wave velocities are initially low for the tuff, which has an initial porosity of $\sim 45 \%$, but both increase by between 25 and $50 \%$ over the effective pressure range of 5 to $80 \mathrm{Mpa}$, corresponding to a decrease of porosity of $\sim 70 \%$. Marked velocity hysteresis, due to inelastic damage processes, is also observed in samples subjected to a pressurisationdepressurisation cycle.

Tomographic seismic velocity distributions obtained from field recordings are in general agreement with the laboratory measurements. Integration of the laboratory ultrasonic and seismic
\end{abstract}


tomography data confirms that the tuffs of the Campi Flegrei caldera are water saturated, and shows that inelastic pore collapse and cracking produced by mechanical and thermal stress can significantly change the velocity properties of Campi Flegrei tuffs at depth. These changes need to be taken into account in accurately interpreting the crustal structure from tomographic data.

\section{Introduction}

The Campi Flegrei caldera, located a few km west of the city of Naples, Southern Italy (Figure 1), is currently one of the most important areas worldwide for detailed volcanological studies. This is because significant uplift (rates up to $1 \mathrm{~m} /$ year) and slow secular subsidence, recognised from marine encrustations on ancient Roman remains, indicate the possibility of renewed volcanic activity that may pose a serious threat to the densely-inhabited Neapolitan area.

Campi Flegrei is a nested caldera formed by a sequence of collapse episodes. The formation of the largest caldera, with a radius of about $6 \mathrm{~km}$, is related to the collapses that followed the eruption of the Campanian Ignimbrite around 35,000 years ago (Rosi et al., 1987). The innermost collapse occurred about 12,000 years ago, and is associated with the major eruption of the Neapolitan yellow tuff. The activity at Campi Flegrei caldera has been characterised by many explosive eruptions from different vents. The last eruption occurred in $1538 \mathrm{AD}$ after several years of rapid ground uplift, and resulted in a high level of damage to buildings and loss of life. More recently, two very large uplift episodes, apparently not followed by eruptions, occurred between 1970 and 1984. These were followed by a period of rapid subsidence (around 5 to $8 \mathrm{~cm} /$ year) that is still in progress.

The scientific community has recently increased its efforts in seeking to understand the eruptive hazard associated with these uplift-subsidence events, both by detailed analysis of ground deformation (Bianchi et al., 1987; Dvorak and Berrino, 1991; 
Bonafede et al., 1986; De Natale et al., 1991; De Natale and Pingue, 1993; De Natale et al., 1997; Bonafede and Mazzanti, 1998) and seismicity (Troise et al., 1997;2003), and by modelling of the overall physics and mechanics of the process (Gaeta et al., 1998; De Natale et al., 2001; Gaeta et al., 2003). One of the key issues related to the recent activity lies in determining the role played by water circulation and thermal-fluid perturbations (Bonafede and Mazzanti, 1998; Gaeta et al., 1998; 2003; De Natale et al., 2001, Troise et al., 2001; Aster and Meyer, 1988). In order to address this, and to be able to model the processes acting within the caldera, detailed knowledge of the crustal structure and the properties of the relevant rocks are required.

In an attempt to reconstruct the crustal structure, Aster and Meyer (1998), presented a three-dimensional velocity model for the central part of the caldera. From their data, they inferred that the rocks were likely to be water saturated. However, their interpretation should be treated with caution, since the resolution was limited by the relatively small number of earthquakes and recording stations, and by the lack of experimental data on the effect of water saturation on wave velocities in tuff.

Zamora et al. 1994 provided the first laboratory measurements of ultrasonic wave velocities on rocks from Campi Flegrei. Compressional (Vp) and shear (Vs) wave velocities were measured at ambient pressure and temperature on core samples from four boreholes, and from a maximum depth of $3 \mathrm{~km}$. Again, they suggested that velocities in water-saturated samples were more representative of in-situ rock conditions than those in dry samples. Differences between their laboratory and available in-situ velocities were interpreted as being due to velocity dispersion between ultrasonic and sonic frequencies and by the elevated pressure and temperature conditions existing at depth. Unfortunately, the location of the wells (at the boundaries of the caldera) and their limited areal distribution do not allow their data to be used for improving the velocity models necessary 
for relocation purposes (Pujol, 2000), despite the caldera symmetry (Zamora et al., 2001). More importantly, velocity variations with depth, which are crucial for relocation techniques, could not be analysed by Zamora et al. 1994, because all their measurements were made only at ambient pressure.

More recently, Vanorio et al. (2002) presented laboratory measurements of both $\mathrm{P}$ and $\mathrm{S}$ wave velocities for a number of volcanic rocks from Italy, including Neapolitan yellow tuff; the main lithology in the Campi Flegrei caldera. Their measurements were made at confining pressures up to $60 \mathrm{MPa}$ and effective pressures up to $45 \mathrm{MPa}$. However, their results are discussed specifically in terms of the activation of different microstructural deformation mechanisms under dry and saturated conditions, and are not used to address the issue of crustal structure.

Here we present a systematic set laboratory measurements of $\mathrm{Vp}$ and $\mathrm{Vs}$ made on samples of the Campi Flegrei tuff. Measurements were made over a range of effective pressures up to $80 \mathrm{MPa}$. We further investigated the effect of temperature on the physical properties of Campi Flegrei tuff by thermal stressing since this can also modify the microstructure by inducing thermal crack damage.

Our overall aim was to simulate the role of increasing depth on the physical properties of the tuff, which is crucial for the reconstruction of crustal structure from tomographic data. Hence, the laboratory data are interpreted jointly with in-situ velocities calculated from a new, local earthquake tomography model that incorporates the largest data set available (331 earthquakes) for the area. One of the key questions we address, from the comparison of laboratory and in-situ measurements, is whether the tuffs are dry or water saturated, as previously hypothesized by Aster and Meyer (1988) because of high $\mathrm{Vp} / \mathrm{Vs}$ ratios and also inferred by Zamora et al. (1994) on the basis of their laboratory measurements. 


\section{Laboratory scale experimental investigation}

\subsection{Methodology}

The material investigated was the Campi Flegrei tuff $(12 \mathrm{ka})$, which is the most abundant and widely distributed lithology in the caldera (Rosi and Sbrana, 1987). It is a strongly heterogeneous pyroclastic flow material, which includes cavities, pumice and crystals of sanidine, pyroxene and biotite (Vanorio et al., 2002). It has an initial porosity of around $45 \%$. In order to take in account the variability due to the heterogeneity of the Campi Flegrei tuff, three blocks of material were collected from depths of a few tens of meters from a quarry located near the village of Pozzuoli. Laboratory measurements were subsequently made on core samples $38 \mathrm{~mm}$ in diameter by $40 \mathrm{~mm}$ long, taken from these blocks.

Ultrasonic wave velocity measurements were made by the pulse-transmission technique inside a fluid-medium hydrostatic pressure vessel. A diagram of the internal arrangement is given as Figure 2. A 900 volt pulser was used to excite two $1 \mathrm{MHz}$ piezoelectric transmitting transducers at one end of the sample, one each for compressional and shear mode. Signals were received by two identical transducers located at the opposite end of the sample. Error in the first arrival time is estimated as approximately $1 \%$ for Pwaves and about 3\% for S-waves (Benson et al., 2004). Measurements were carried out on both dry and wet samples at effective pressures up to $80 \mathrm{MPa}$. Here we define the effective pressure as simple the difference between the confining pressure and the pore fluid pressure. Dry measurements were made on samples that had been dried in an oven at $80^{\circ} \mathrm{C}$ for a minimum of 24 hours. Previous experience suggests that little if any thermal crack damage occurs at this temperature. Wet measurements were made on samples that 
had been vacuum saturated with distilled water for a minimum of 24 hours. Since the tuff is mechanically very weak, a low pore fluid pressure of $1.5 \mathrm{MPa}$ was used throughout in order to prevent damage to the microstructure. Effective pressure was increased in steps of $5 \mathrm{MPa}$ up to $40 \mathrm{MPa}$ and steps of $10 \mathrm{MPa}$ for all higher pressures. The change in sample porosity was measured from the volume of water expelled during each incremental increase in effective pressure. This decrease in pore volume is attributed to the closure of cracks and pores with increase in pressure (Benson et al., 2004).

\subsection{Thermal treatment}

Selected samples were thermally treated by heating either to $300^{\circ}$ or $600^{\circ} \mathrm{C}$ at a rate of $1{ }^{\circ} \mathrm{C} / \mathrm{min}$ in a tube furnace. In order to monitor the amount of induced thermal damage, the output of acoustic emissions (AEs) was recorded throughout each thermal stressing experiment (Vinciguerra et al., 2005). A threshold amplitude of $33 \mathrm{~dB}$ was set to eliminate extraneous background noise.

Figure 3 shows that relatively continuous $\mathrm{AE}$ activity is observed up to about $200^{\circ} \mathrm{C}$. This is followed by a general decrease in the AE rate, but with bursts of activity around $400^{\circ} \mathrm{C}$ and from $540^{\circ}$ to $600^{\circ} \mathrm{C}$. This suggests the action of different deformation mechanisms. The lower temperatures activity is likely to be due to thermal expansion mismatch between different mineral phases, while dehydration of the zeolite phases present and associated thermal cracking are considered to be responsible for the higher temperature bursts (De' Gennaro et al., 1999). However, study of the time evolution of AE activity was not our primary goal in this study. We merely use the thermal stressing as a method of investigating thermally-induced damage in our samples, and its effect on elastic wave velocities. 


\subsection{Results}

Simultaneous measurements of $\mathrm{P}$ and $\mathrm{S}$ wave ultrasonic velocities on both dry and saturated samples have been made at effective pressures from 5 to $80 \mathrm{MPa}$ during both pressurisation and depressurisation cycles. Measurements were made on the following samples types: (a) non-thermally treated, (b) thermally treated to $300^{\circ} \mathrm{C}$ and (c) thermally treated to $600^{\circ} \mathrm{C}$. The change in length of samples resulting from the application of hydrostatic pressure has been calibrated, and times-of-flight corrected for this effect. Figure 4 shows one such calibration curve, with a reduction in sample length of about $0.75 \%$ at the maximum effective pressure of $80 \mathrm{MPa}$. All velocities reported here have been corrected for the effect of sample shortening.

Figures 5 and 6 show, respectively, $\mathrm{P}$ and $\mathrm{S}$ wave velocities measured on dry samples as a function of confining pressure. At the lowest pressures it was often difficult to pick the first arrival due to its low amplitude. The process became progressively easier as the amplitude increased at higher pressures. Initial velocities are very low, as would be expected for a material with an initial porosity of around $45 \%$. However, all the velocities increase significantly with increasing confining pressure; by between 25 and $50 \%$ over the pressure range 5 to $80 \mathrm{MPa}$. This is true for both $\mathrm{P}$ and $\mathrm{S}$ waves, for samples from all three blocks and for both heat-treated and non-heat-treated samples. Samples that had been heat-treated to $600^{\circ} \mathrm{C}$ (open symbols on Figures 5 and 6) had velocities lower than those of non-heat-treated samples. This is more evident for S waves (Figure 6) than for $\mathrm{P}$ waves (Figure 5). By contrast, samples that had been heat-treated to only $300^{\circ} \mathrm{C}$ (asterisks on Figures 5 and 6) show similar velocities to non-heat-treated samples. These observations support the suggestion that dehydration of the zeolite phases and associated cracking above $400^{\circ} \mathrm{C}$ is the primary deformation mechanism producing both acoustic emissions and the reduction in velocity. The pattern of velocity change with increasing 
pressure is complicated by the fact that different changes are observed for the three different sample blocks. This is illustrated in Figure 7, where averaged normalised velocities are given for samples from each block. These observations support the idea that the compaction mechanism responsible for the velocity increases is strongly influenced by the material heterogeneity and especially the large inclusions within the rock matrix.

Figure 8 shows an example of the significant hysteretic in velocity that is observed when samples are first pressurised to $80 \mathrm{MPa}$ and then depressurised. Both Vp and Vs are about $10 \%$ higher after depressurisation than before initial pressurisation. This implies that at least part of the deformation responsible for the sample compaction is inelastic and irreversible. Figure 9 shows a cross-section of a sample before (upper image) and after (lower image) a pressurisation-depressurisation cycle. Note the cracking present in the post-test sample that is not present in the pre-test sample. Further, Figure 10 shows the elevation of a sample recovered after a pressurisation-depressurisation cycle. Note the large radial cracks that have developed during the cycle. These are very reminiscent of the stress-relief cracking, known as "core-disking", that commonly occurs in cores recovered from depth in boreholes. It is unlikely that the cracking we observe in post-test samples occurred during the pressurisation part of the cycle, but highly likely that it occurred during depressurisation. In this case, we would expect the presence of cracks to decrease velocities. However, since the depressurisation velocities are higher than the pressurisation velocities at each pressure, we conclude that the inelastic part of the deformation is even more significant than the velocity hysteresis data suggests.

Only P wave velocity measurements were made on water-saturated samples, since S wave arrivals were so strongly attenuated that arrival times could not be measured accurately. $\mathrm{P}$ wave velocities and corresponding porosity values inferred from pore volume changes are shown in Figure 11a,b. Overall, the data show the same trend as that 
observed for the dry measurements, with increases in velocity of about 30 to $40 \%$ over the pressure interval 5 to $80 \mathrm{MPa}$. The saturated samples have velocities approximately 10 to $15 \%$ higher than dry samples at the same pressure, and the change in velocity is even more marked at low pressures. Again, almost identical patterns are seen in the saturated samples for heat-treated samples and in the velocity hysteresis. Crucially, the velocity increase corresponds to a porosity decrease of $\sim 50 \%$ at $40 \mathrm{MPa}$ and $\sim 70 \%$ at $80 \mathrm{MPa}$, showing that the main deformation mechanism for water-saturated samples is inelastic pore collapse. Since the change in velocity occurs over the same pressure range as in the dry samples and the pore pressure applied was very low (1.5MPa), it is suggested that a similar porosity decrease occurred during pressurisation of the dry samples.

Taken together, we suggest that the high initial (45\%) and the low final (15\%) porosity of the material, the velocity hysteresis and the post-test images, provide strong evidence that the dominant deformation mechanism is inelastic pore collapse. This further suggests that hydrostatic pressure alone is able to drive mechanical damage of the tuff under in-situ conditions at depth at Campi Flegrei.

\section{Field velocity determinations by seismic tomography}

Local earthquakes that occurred at Campi Flegrei in the period 1970-1984, i.e. during the most recent episodes of unrest, provide a good database for tomographic reconstruction of seismic velocities in the depth range 0 to $4 \mathrm{~km}$ (Troise et al., 2003; De Natale et al., 1995). Seismograms of these earthquakes were recorded by both permanent (analogue) and temporary (digital) stations. A map showing the locations of the seismic stations operating during the above period, and vertical sections of earthquake locations calculated from an earlier 3-D model (Presti et al., 2005), is presented as Figure 1. 
In this study, $3757 \mathrm{P}$ wave and $\mathrm{S}$ wave travel times from a set of 451 earthquakes were inverted to obtain $\mathrm{P}$ wave and $\mathrm{S}$ wave velocities. From this full dataset, a subset of 331 earthquakes with a minimum of $8 \mathrm{P}$ wave and/or $\mathrm{S}$ wave records and a maximum angular gap between seismic stations of $180^{\circ}$ was selected. Three-dimensional tomographic images of both Vp and Vs were generated using the simultaneous inversion package SIMULPS13Q (Thurber, 1993; Eberhart-Philips, 1993) which incorporates rigorous finite difference 3-D ray tracing. The starting model was taken as the best fit homogeneous velocity model. This is characterised by a Vp value $3.0 \mathrm{~km} / \mathrm{s}$ and a $\mathrm{Vp} / \mathrm{Vs}$ ratio of 1.8, which gives a global RMS misfit of 0.1 seconds. The 3-D heterogeneous model was specified on a grid having $1 \mathrm{~km}$ spacing in latitude, longitude and depth. The inversion was stopped after four iterations when the RMS misfit was reduced by $40 \%$ to a final value of 0.10 .

We present the results for four depths intervals where the resolution was highest. Results from the final Vp model are shown in Figure 12. The horizontal velocity distribution at each of the four depths is given in Figure 12a, and vertical cross-sections of Vp, oriented N-S and E-W, are given in Figure 12b. Model results for Vp/Vs ratios are presented in exactly the same way in Figure 13. The reference point of zero latitude and zero longitude is the town of Pozzuoli.

The $\mathrm{P}$ wave velocity distributions characterise the structure of the inner caldera (Rosi and Sbrana, 1987) as a collapsed area filled with pyroclastic products from the recent eruptions (low velocities), evident to a depth of about $4 \mathrm{~km}$ and a radius of about 3 $\mathrm{km}$ around Pozzuoli. Since the majority of the recording stations were located within the caldera itself (Figure 1), the resolution of the caldera rims is not as good as the inner part. However, Figure $12 \mathrm{~b}$ does suggest a basin-like structure at depth. The average $\mathrm{P}$ wave velocity in the collapsed caldera basin is around $2.9 \mathrm{~km} / \mathrm{s}$, with the highest velocities 
(around $3.6 \mathrm{~km} / \mathrm{s}$ ) occurring at the caldera centre. The average $\mathrm{S}$ wave velocity, inferred from $\mathrm{Vp}$ and the $\mathrm{Vp} / \mathrm{Vs}$ ratio (Figure 13) is about $1.6 \mathrm{~km} / \mathrm{s}$, with the highest $\mathrm{Vp} / \mathrm{Vs}$ ratio (around 2.0) also occurring evidenced at the caldera centre. Taken together, these results are entirely consistent with a caldera filled with weak, relatively incompetent rock that is fractured and fluid saturated (Aster and Meyer, 1988; O’Connel and Budiansky).

\section{Discussion and Conclusions}

When comparing seismic velocities $(10$ to $100 \mathrm{~Hz})$ at the field scale with ultrasonic velocities $(100 \mathrm{kHz}$ to $1 \mathrm{MHz})$ at the laboratory scale, one has to consider both the frequency dependence and the difference in rock volume investigated. However, even where the scaling relation cannot be addressed directly, it has been postulated that, for dry conditions, cracks and faults exert approximately the same influence on the propagation of elastic waves regardless of frequency (Zamora et al., 1994 and references therein). Furthermore, the degree of dispersion under saturated conditions for highly attenuating rocks, such as the Campi Flegrei tuff, has been reported to be in the range 25 to $50 \%$ (Aster and Meyer, 1988). However, dispersion drops off rapidly to less then $10 \%$ when effective pressure is increased (Zamora et al., 1994 and references therein). Thus, for the values of Vp and Vs reported here, differences appear to be of the order of 0.2 to $0.3 \mathrm{~km} / \mathrm{s}$ might be expected between laboratory-scale measurements and field-scale determinations. From these considerations, the average $\mathrm{P}$ wave velocity determined for the Campi Flegrei caldera (about $2.9 \mathrm{~km} / \mathrm{s}$ ) is more consistent with the laboratory measurements under saturated conditions, since they are significantly higher than for dry conditions. In detail, 
by considering the laboratory Vp measurements performed in dry conditions (Fig. 6), one can observe that, at simulated depths of $2 \mathrm{~km}$ (about $40 \mathrm{Mpa}$ ), values range from $2.3 \mathrm{~km} / \mathrm{s}$ to $2.5 \mathrm{~km} / \mathrm{s}$. On the other hand, by considering $\mathrm{Vp}$ measurements performed in wet conditions (Fig. 7), laboratory determinations at equivalent depths range from 2.6 to 3.2 $\mathrm{km} / \mathrm{s}$, reproducing the average value of $2.9 \mathrm{~km} / \mathrm{s}$ obtained by the field tomography.

The average field-scale $\mathrm{S}$ wave velocity inferred from $\mathrm{Vp}$ and the $\mathrm{Vp} / \mathrm{Vs}$ ratio is about $1.6 \mathrm{~km} / \mathrm{s}$, lower than the dry laboratory measurements made at the equivalent pressure. Even though laboratory $\mathrm{S}$ wave velocity measurements under saturated conditions are not available, the large amplitude attenuation that prohibited such measurements strongly suggests that saturated $\mathrm{S}$ wave velocities are likely to be lower than those for dry samples. Hence, the velocities in water-saturated samples appear to be more representative of in-situ rock conditions than those in dry samples, in agreement with the saturation and high degree of fracturing reported for the caldera (Aster and Meyer, 1988; O’Connel and Budiansky, 1976).

The effect of increasing hydrostatic pressure on wave velocities is strongly influenced by the geometry of the void space, and particularly by the presence of cracks and pore fluids. $\mathrm{P}$ and $\mathrm{S}$ wave velocities measured in the laboratory show the expected increasing trend with increase in pressure. Velocities increase by between 25 and $50 \%$ over the pressure range $5 \mathrm{MPa}$ to $75 \mathrm{MPa}$. These observations, taken together with measurements of porosity decrease and imagesof the samples from before and after pressurisation, show that pressure changes induce major damage in the tuff through inelastic pore collapse and enhanced cracking. Despite the fact that variations in velocity with increasing depth in the field-scale tomographic study are affected by the resolution of the velocity model (due to the degree of spatial clustering), an overall average increase of about $0.3 \mathrm{~km} / \mathrm{s}$ is observed to occur between 2 and $4 \mathrm{~km}$ depth (Figures 12 and 13). 
Changes in velocities at the bottom of the caldera, at about $4 \mathrm{~km}$ depth, are in agreement with the range expected (10-30\%) from theoretical calculations (Zamora et al. 1994).

The effect on velocities of raising the temperature appears to only become significant when it is high enough to cause some physical change. For the case of the Campi Flegrei tuff, this appears to be the volume change and generation of free water associated with the dehydration of zeolite phases, which can lead to thermal crack damage. In laboratory samples, thermal treatment to $600^{\circ} \mathrm{C}$ resulted in velocity decreases of about 0.3 to $0.5 \mathrm{~km} / \mathrm{s}$ (i.e. about $10 \%$ ) with respect to non-heat-treated samples. This is consistent with velocity changes due to increased temperature of around $10 \%$ reported by (Zamora et al. 1994).

Overall, we have shown that structural interpretations from tomographic studies can be improved significantly if the effects of changes in rock velocities due to changes in microstructure caused by changes in environmental variables are taken into account. In particular, changes in effective pressure conditions, changes in temperature and changes the degree of water saturation with depth all impact significantly on the propagation of elastic waves.

Acknowledgements. This work has been supported by EU contract EVG1-CT-2001-00047 and British Council exchange programme is thanked for supporting S.V. and C.T. work at University College of London. Giuseppe Mastrolorenzo, Lucia Pappalardo and Monica Piochi are thanked for fruitful discussions. Two anonymous reviewers are thanked are acknowledged for improving the quality of the paper. 


\section{References}

Aster, R. C. and Meyer, R. P., 3-dimensional velocity structure and hypocenter distribution in the Campi Flegrei caldera, Italy. Tectonophysics, 1988, 149, 195 218.

Benson, P.M., Meredith, P.G., Platzman, E.S. and White, R.E., Pore fabric shape anisotropy in porous sandstone and its relation to elastic and permeability anisotropy under hydrostatic pressure. Int. J. Rock Mech., 2005, in press.

Bianchi, R., Cordini, A., Federico, C., Giberti, G., Lanciano, P., Pozzi, J.P., Sartoris, G. and Scandone, R., Modeling of surface deformation in volcanic areas: the 19701972 and 1982-1984 crises of Campi Flegrei, Italy. J. Geophys. Res., 1987, 92, B13, 14139-14150.

Bonafede, M. and Mazzanti M., Modelling gravity variations consistent with ground deformation in the Campi Flegrei caldera (Italy). J. Volcanol. Geotherm. Res., 1998, 81, 137-157.

Bonafede, M., Dragoni M. and Quareni F., Displacements and stress fields produced by a centre of dilatation and by a pressure source in a viscoelastic half-space: application to the study of ground deformation and seismic activity at Campi Flegrei, Italy. Geophys. J. R. Astr. Soc., 1986, 87, 455-485.

De' Gennaro, M., Incoronato, A., Mastrolorenzo, G., Adabbo, M. and Spina, G., Depositional mechanisms and alteration processes in different types of pyroclastic deposits from Campi Flegrei volcanic field (Southern Italy). Journ. Volc. Geoth. Res., 1999, 91, 303-320.

De Natale, G., Iannacone, G. and Virieux, J.A., A probability method for earthquake focal mechanisms. Geophys. Res. Letters, 1991, 18,4.

De Natale, G. and Pingue, F., Ground deformations in collapsed caldera structures. J. Volcanol. Geotherm. Res., 1993, 57, 19-38.

De Natale, G., Petrazzuoli, S.M. and Pingue, F., The effect of collapse structures on ground deformations in calderas. Geophys. Res. Letters, 1997, 24,13,1555-1558.

De Natale, G., Troise, C. and Pingue, F., A mechanical fluid-dynamical model for ground movements at Campi Flegrei caldera. Journ. Geodynamics, 2001, 32, 487-517.

De Natale, G., Zollo, A., Ferraro, A. and Virieux, J., Accurate fault mechanism determinations for a 1984 earthquake swarm at Campi Flegrei caldera (Italy) 
during an unrest episode: Implications for volcanological research. J. Geophys. Res., 1995, 100, (B12), 24167-24185.

Dvorak, J. J. and Berrino, D., Recent ground movement and seismic activity in Campi Flegrei, southern Italy: episodic growth of a resurgent dome. J. Geophys. Res., 1991, 96, B2, 2309-2323.

Eberhart-Phillips, D., Local earthquake tomography: earthquake source regions. In Seismic Tomography: Theory and Practice, 1993, edited by H. M. Iyer and K. Hirahara.

Gaeta, F.S., De Natale, G., Peluso, F., Mastrolorenzo, G., Castagnolo, D., Troise, C., Pingue, F., Mita, D.G. and Rossano, S., Genesis and evolution of unrest episodes at Campi Flegrei caldera: The role of thermal fluid-dynamical processes in the geothermal system. J. Geophys. Res., 1998, 103, 921-933.

Gaeta, F.S., Peluso, F., Arienzo, I., Castagnolo, D., De Natale, G., Milano, G., Albanese, C. and Mita D.G., A physical appraisal of a new aspect of bradyseism: The miniuplifts. J. Geophys. Res., 2003, 108, B08, 10.1029/2002JB001913.

O’ Connel, R. and Budiansky, B., Seismic velocities in dry and saturated cracked solids. J. Geophys. Res., 1976, 79:5413-5426.

Presti, D., Troise, C. and De Natale, G., Probabilistic location of seismic sequences in heterogeneous media. Bull. Seism. Soc. Amer., 2005, in press.

Pujol, J., Comment on "Laboratory measurements of ultrasonic wave velocities in rocks from the Campi Flegrei volcanic system and their relation to other field data" by M. Zamora, G. Sartoris, and W. Chelini. J. Geophys. Res., 2000, 105(B9), 2153721542, 10.1029/2000JB900018.

Rosi, M. and Sbrana, A., Phlegraean Fields: Rome. Quaderni de "La Ricerca Scientifica", 1987, v.9 no. 114,175 p.

Thurber, C. H., Local earthquake tomography: velocities and Vp/Vs - theory. In Seismic Tomography: Theory and Practice, 1993, edited by H. M. Iyer and K. Hirahara.

Troise, C., De Natale, G. and Pingue, F., A model for earthquake generation during unrest episodes at Campi Flegrei and Rabaul calderas. Geophys. Res. Letters, 1997, $24,13,1575-1578$

Troise, C., Castagnolo, F., Peluso, F., Gaeta, F.S., Mastrolorenzo, G. and De Natale, G., A 2D mechanical-thermal fluid-dynamical model for geothermal system at calderas: An application to Campi Flegrei. J. Volcanol. Geotherm. Res., 2001, 109, 1-12. 
Troise, C., Pingue, F. and De Natale, G., Coulomb stress changes at calderas: modeling the seismicity of Campi Flegrei (Southern Italy). J. Geophys. Res., 2003, vol. 108, NO. B6, 2292, doi:10.1029/2002JB002006.

Vanorio, T., Prasad, M., Patella, D. and Nur, A., Ultrasonic velocity measurements in volcanic rocks: correlation with microtexture. Geophys. J. International, 2002, 149, 22-36.

Vinciguerra, S., Trovato, C., Meredith, P.G. and Benson, P. M., , Relating seismic velocities, thermal cracking and permeability in Mt. Etna and Iceland basalts. . Int. J. Rock Mech., 2004, in press.

Zamora, M., Sartoris G. and Chelini W., Laboratory measurements of ultrasonic wave velocities in rocks from the Campi Flegrei volcanic system and their relation to other field data. J. Geophys. Res., 1994, 99(B7), 13553-13562, 10.1029/94JB00121.

Zamora, M., Sartoris G. and Chelini W., Reply to comment by Jose Pujol on "Laboratory measurements of ultrasonic wave velocities in rocks from the Campi Flegrei volcanic system and their relation to other field data”. J. Geophys. Res., 2001, 106(B2), 2163-2166, 10.1029/2000JB900017. 


\section{Figure captions}

Figure 1. (a) Map of the Campanian volcanic area. The inset shows the locations of the permanent recording stations operating in the Campi Flegrei area; (b) E-W and N$\mathrm{S}$ depth sections of locations for the 331 Campi Flegrei earthquakes used in this study, determined by the Bayloc method [21].

Figure 2. Schematic diagram of the measurement assembly for velocity and pore fluid measurements within the hydrostatic pressure vessel.

Figure 3. (a) Amplitude of $\mathrm{AE}$ hits, and (b) cumulative number of $\mathrm{AE}$ hits, as functions of temperature for heat treatment of a tuff sample to $600^{\circ} \mathrm{C}$.

Figure 4. Sample shortening $(\Delta \mathrm{L})$ as a function of effective pressure. Solid triangles represent the shortening measured after application of 15, 40 and $80 \mathrm{MPa}$ effective pressure. The dashed line is a least-squares fit to the data.

Figure 5. Plot of $\mathrm{P}$ wave velocities as a function of confining pressure for samples tested dry. Solid symbols denote non-heat-treated samples, asterisks denote samples heat-treated to $300^{\circ} \mathrm{C}$, and open symbols denote samples heat-treated to $600^{\circ} \mathrm{C}$.

Figure 6. Plot of $\mathrm{S}$ wave velocities as a function of confining pressure for samples tested dry. Solid symbols denote non-heat-treated samples, asterisks denote samples heat-treated to $300^{\circ} \mathrm{C}$, and open symbols denote samples heat-treated to $600^{\circ} \mathrm{C}$.

Figure 7. Plots of normalised (a) $\mathrm{P}$ and (b) $\mathrm{S}$ wave velocities for the 3 different sample blocks as a function of confining pressure. Different symbols are used to distinguish the three blocks. All data are for dry measurements from Figures 5 and 6.

Figure 8. Example of velocity hysteresis for both $\mathrm{P}$ waves (squares) and $\mathrm{S}$ waves (triangles). Solid symbols denote measurements made during pressurisation, and open symbols denote measurements made during depressurisation.

Figure 9. Photographs of a cross-section of a tuff sample before (top) and after (bottom) a pressurisation and depressurisation cycle to $80 \mathrm{MPa}$. Both pore collapse and new cracks are induced by the pressurisation-depressurisation cycle.

Figure 10. Photograph of the elevation of a tuff sample after a full pressurisation and depressurisation cycle to $80 \mathrm{MPa}$. Note the major radial cracks across the sample, reminiscent of core-disking due to stress relief.

Figure 11. Plot of (a) P wave velocities and (b) porosity as a function of effective pressure for water-saturated samples. Open symbols denote non-heat-treated samples, and solid symbols denote the sample heat-treated to $600^{\circ} \mathrm{C}$.

Figure 12. Tomographic maps of the $\mathrm{P}$ wave velocity distribution at Campi Flegrei. The $(0,0)$ reference point is located at the town of Pozzuoli (Latitude: $40^{\circ} 49.22$, 
Longitude: $14^{\circ}$ 07.08), and the coastline is also shown for reference. (a) Horizontal velocity distributions at depths of $1,2,3$, and $4 \mathrm{~km}$, and (b) vertical velocity sections with depth, oriented E-W (A'-A) and N-S (B'-B).

Figure 13. Tomographic maps of the $\mathrm{Vp} / \mathrm{Vs}$ velocity ratio distribution at Campi Flegrei. Again, the reference point is the town of Pozzuoli and the coastline is shown. (a) Horizontal $\mathrm{Vp} / \mathrm{Vs}$ distributions at depths of 1, 2, 3, and $4 \mathrm{~km}$, and (b) vertical $\mathrm{Vp} / \mathrm{Vs}$ sections with depth, oriented E-W (A'-A) and N-S (B'-B). 
Fig. 1

a)

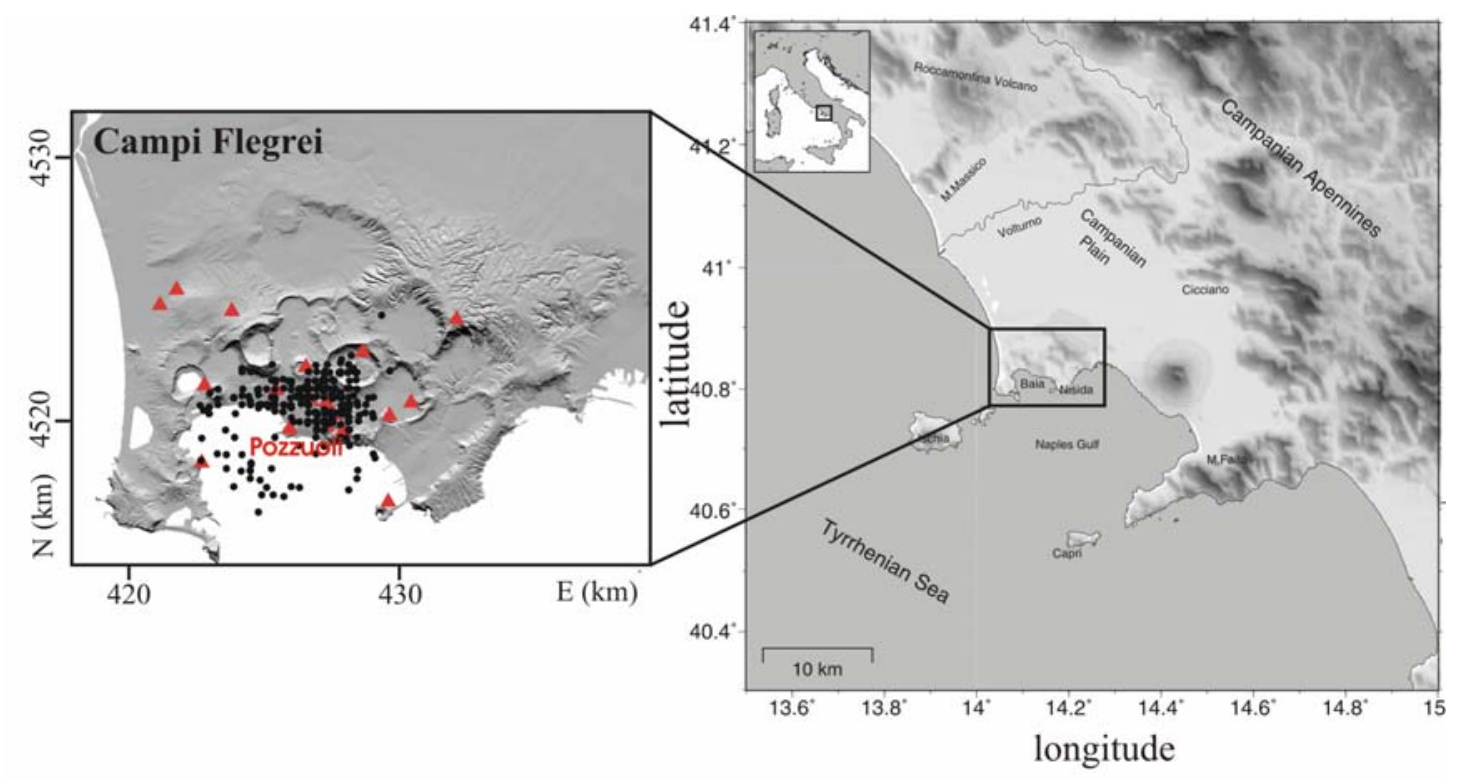

b)

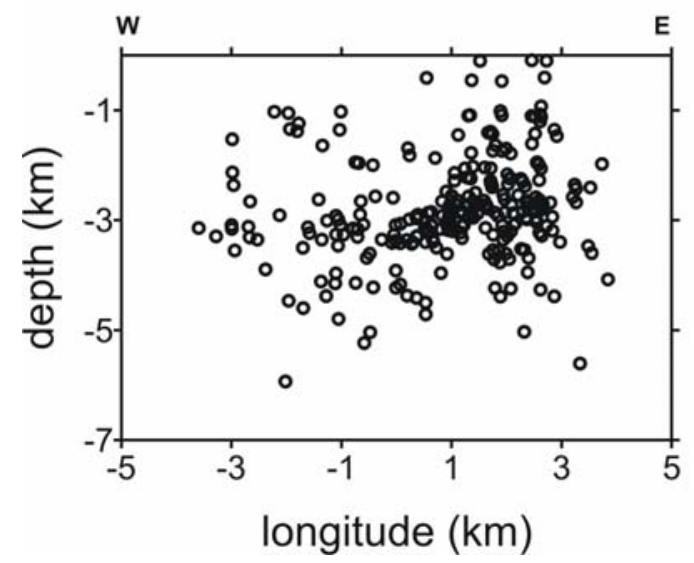

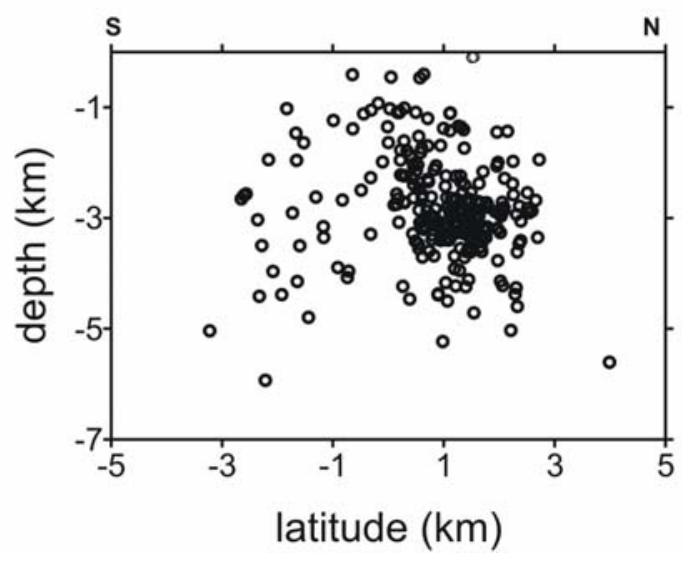


Fig. 2

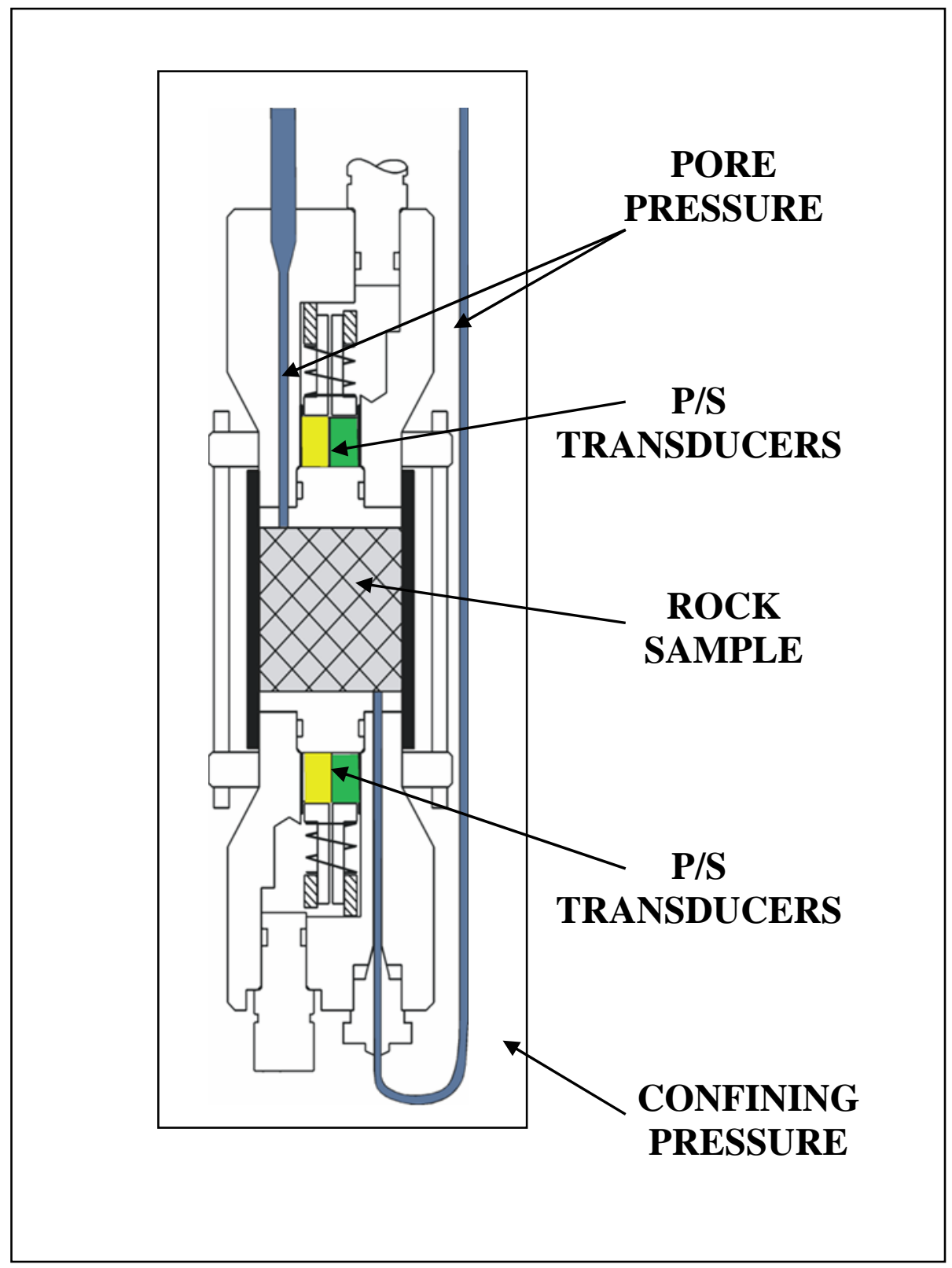


Fig. 3

a

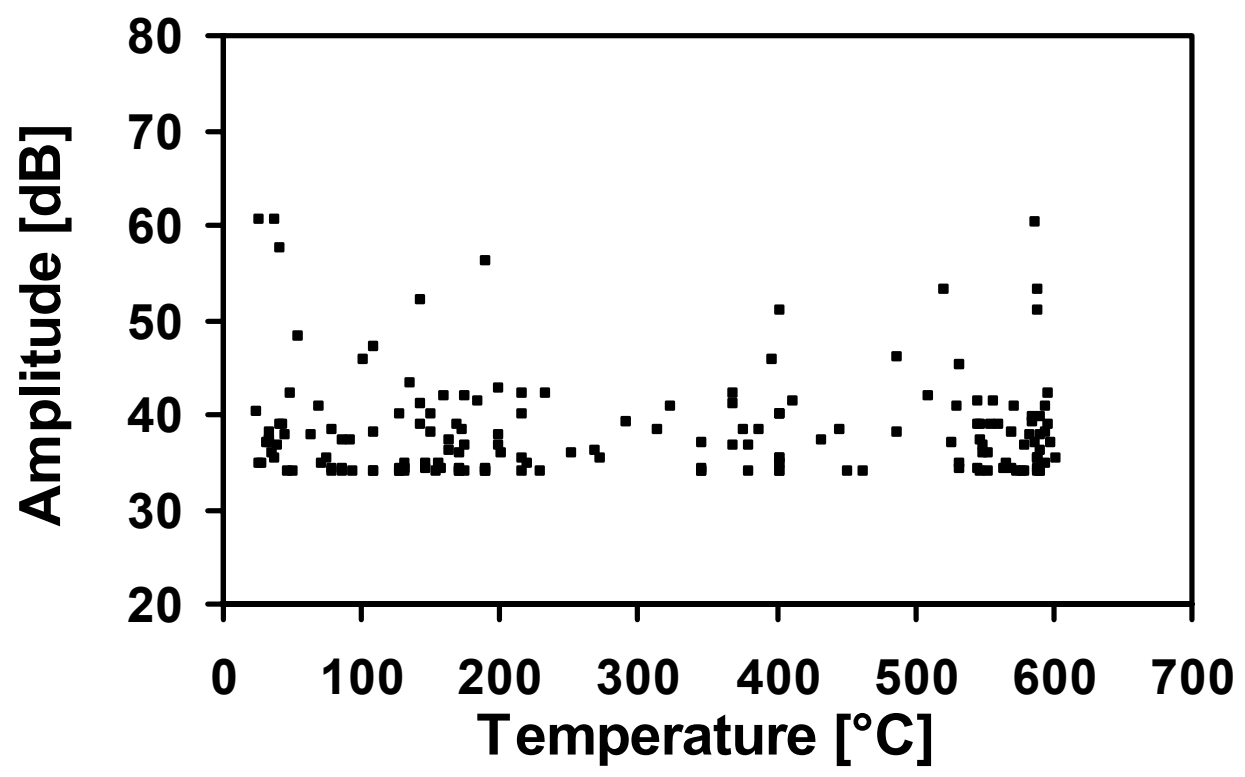

b

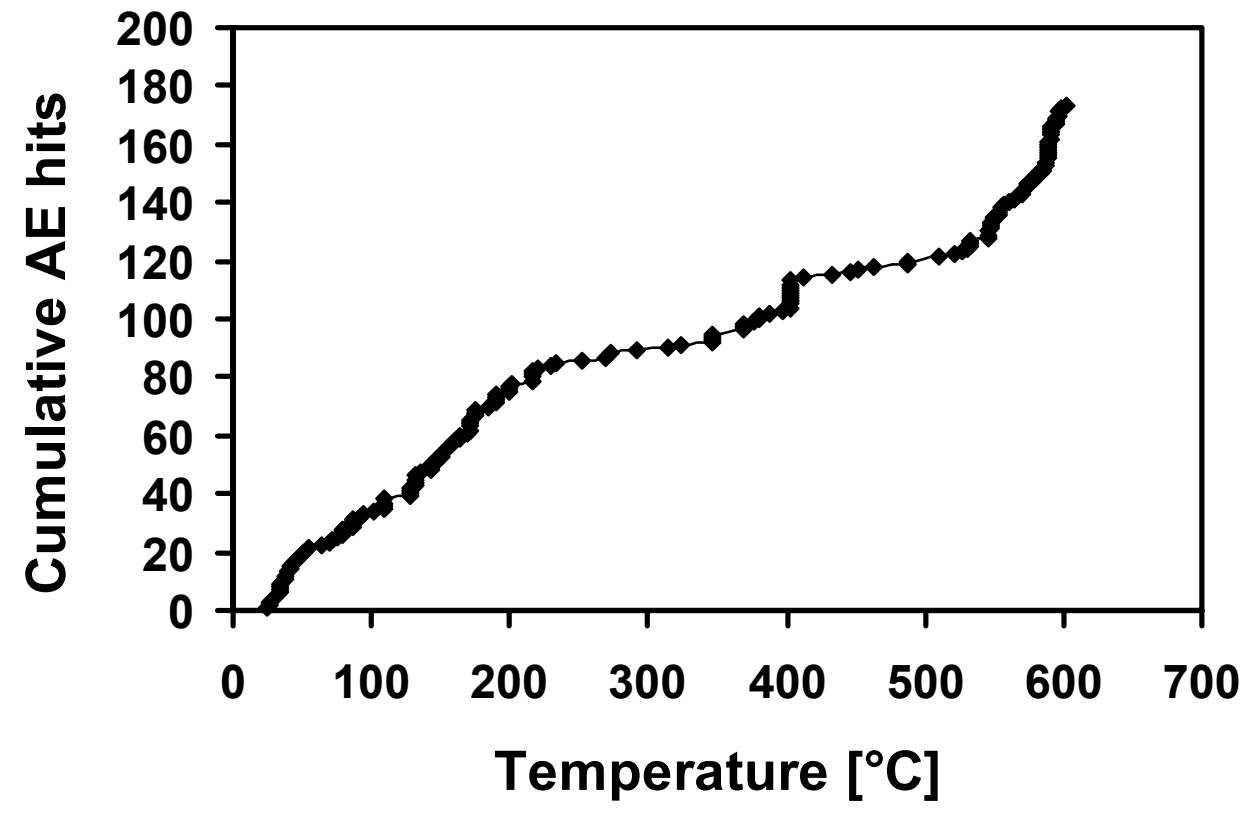


Fig. 4

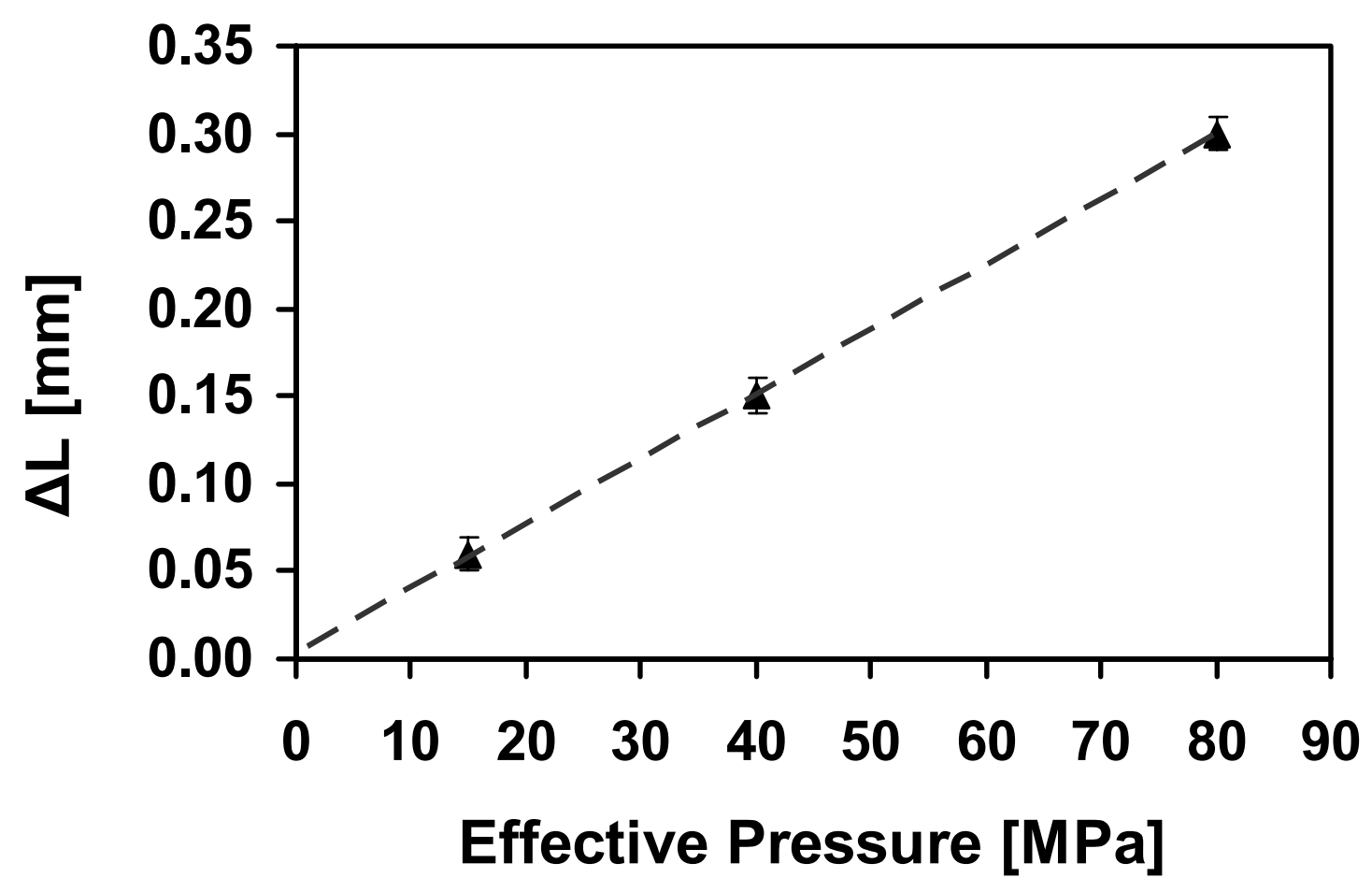


Fig. 5

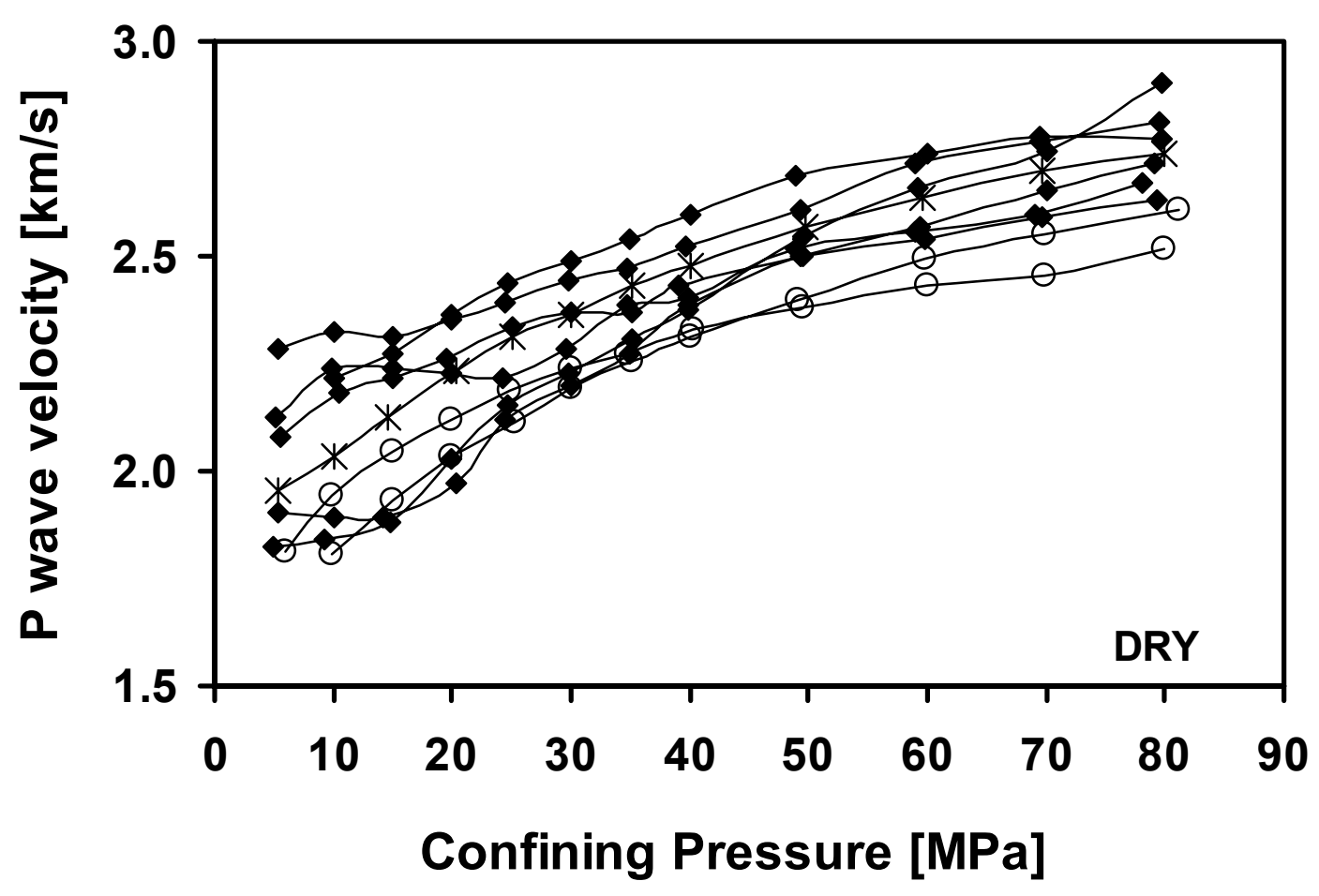


Fig. 6

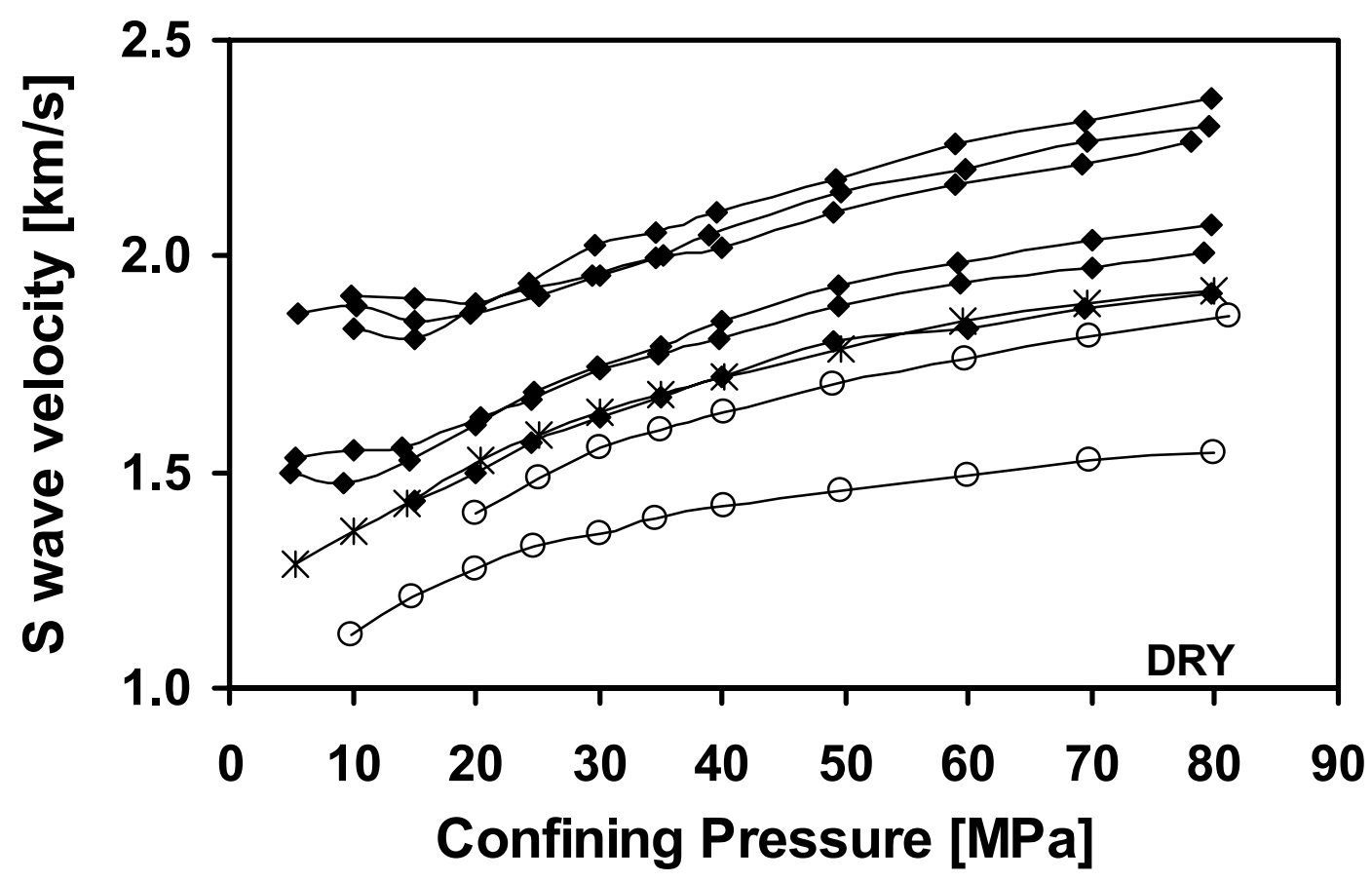


Fig. 7

a

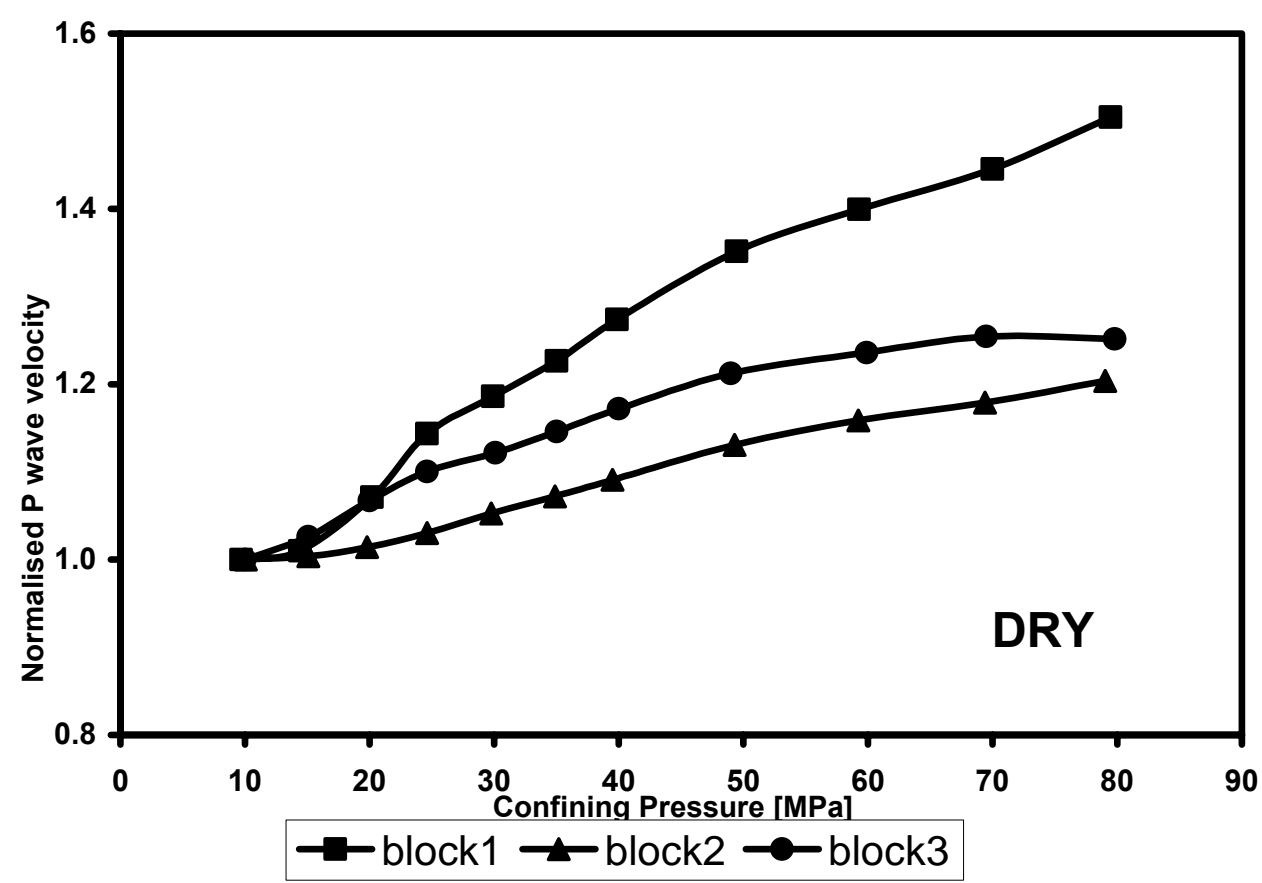

b

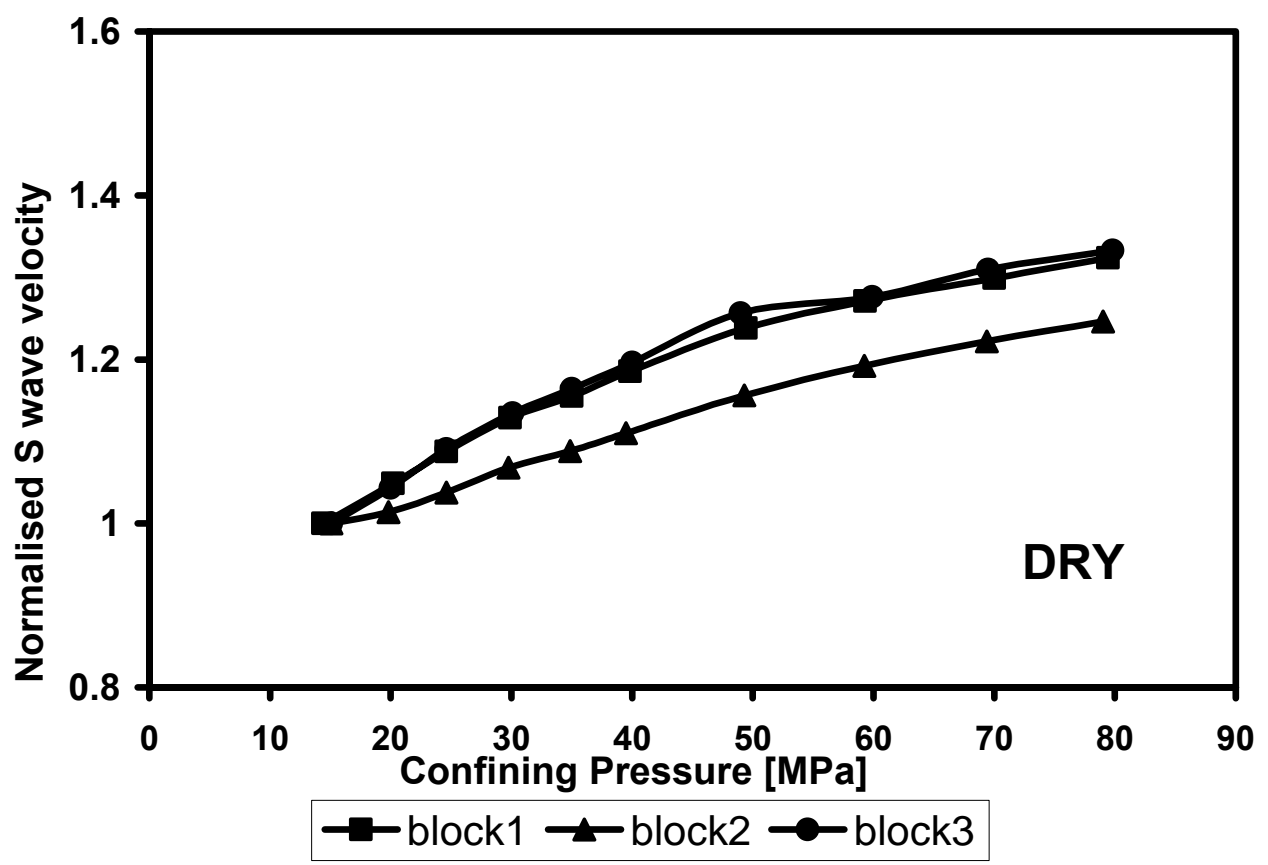


Fig. 8

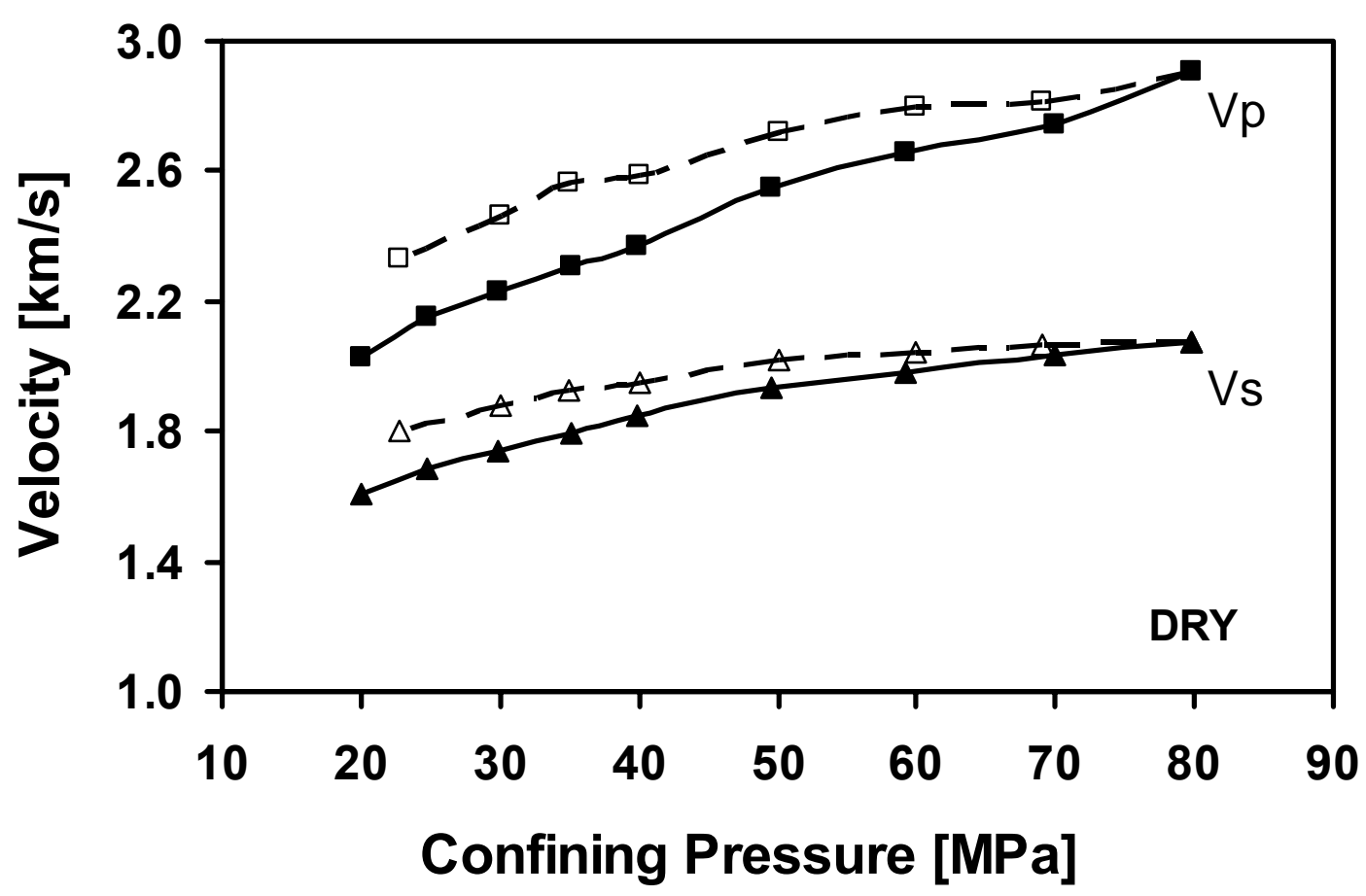


Fig. 9
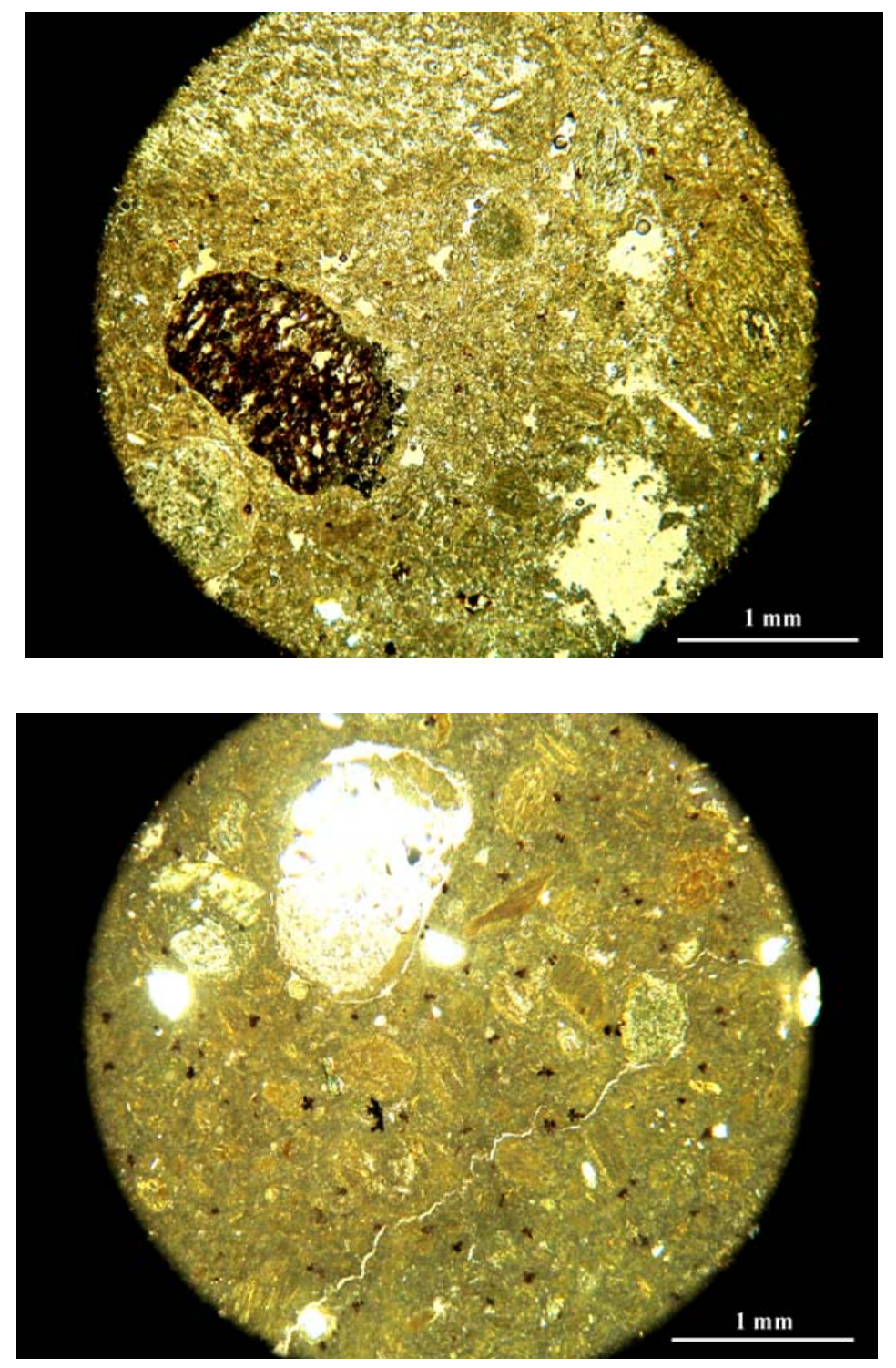
Fig. 10

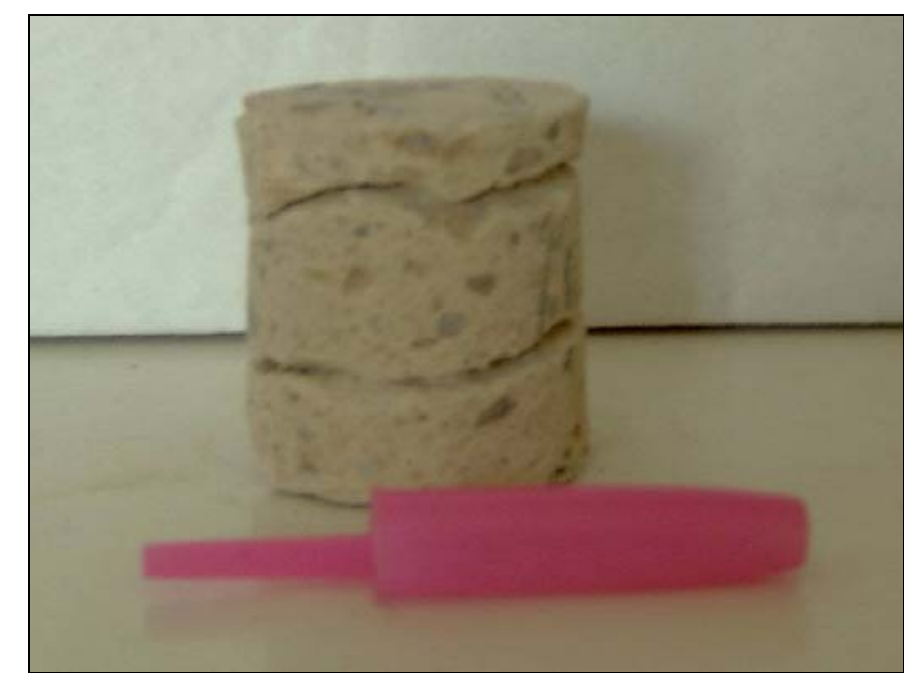


Fig. 11

a

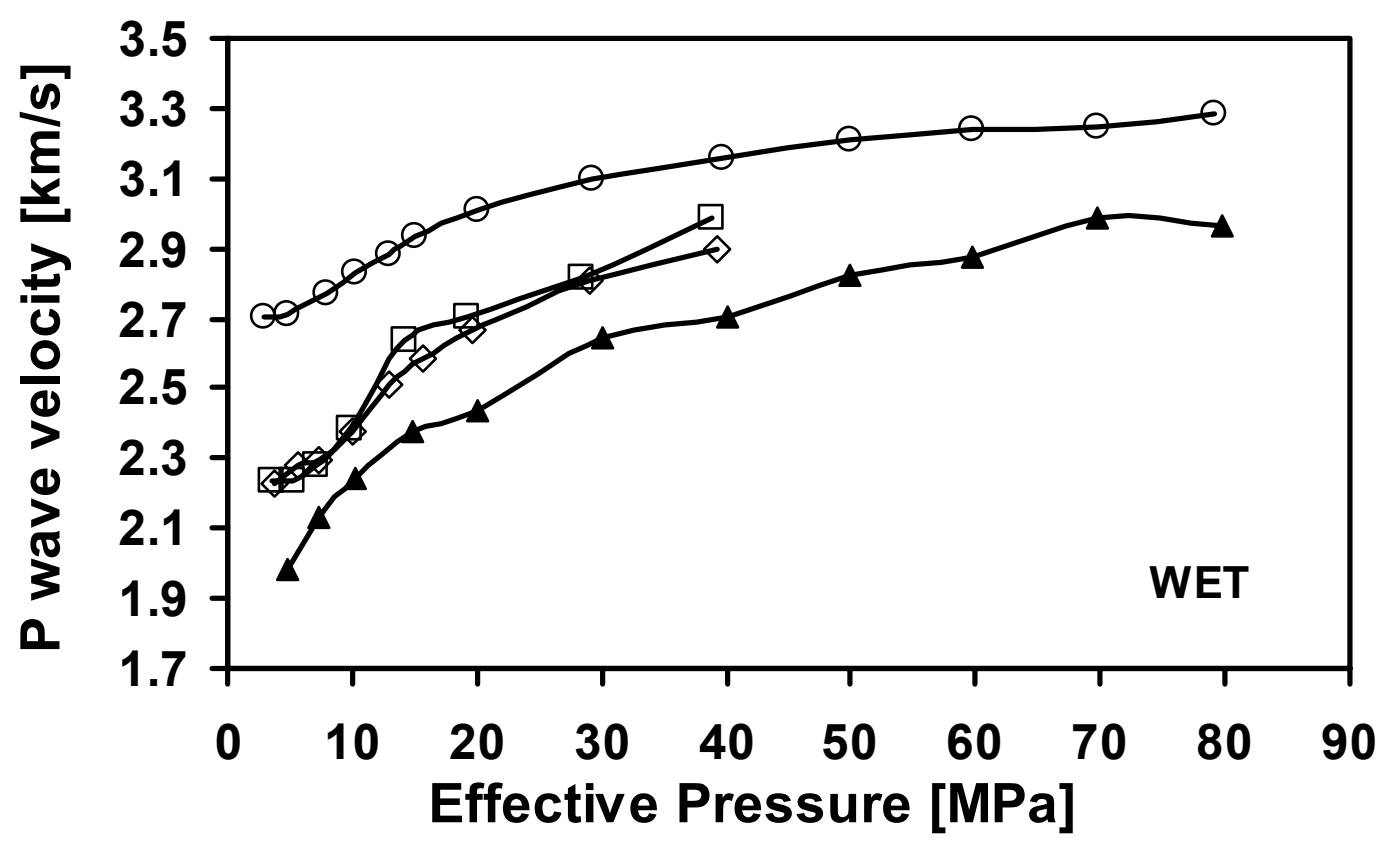

b

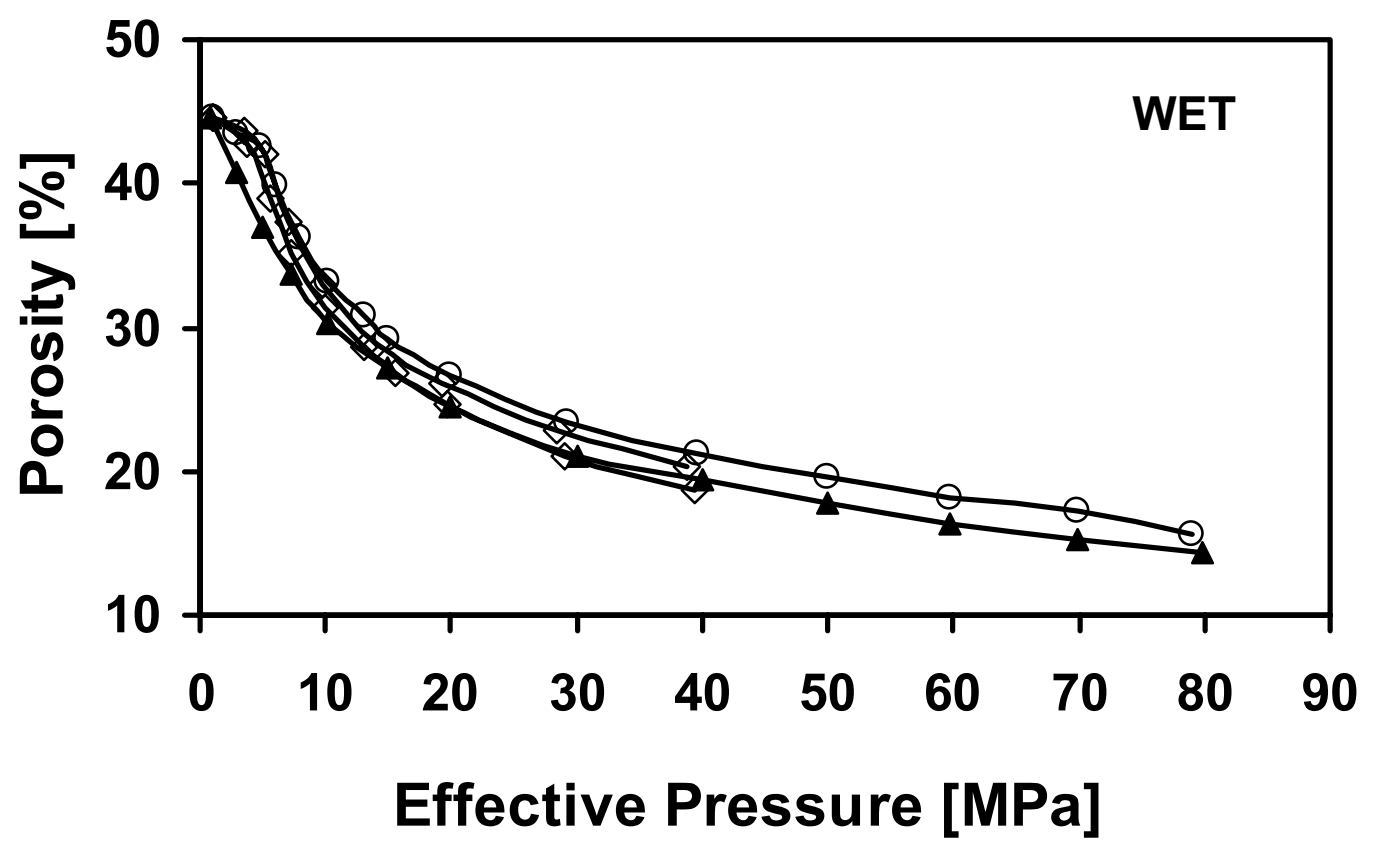


Fig. 12

a
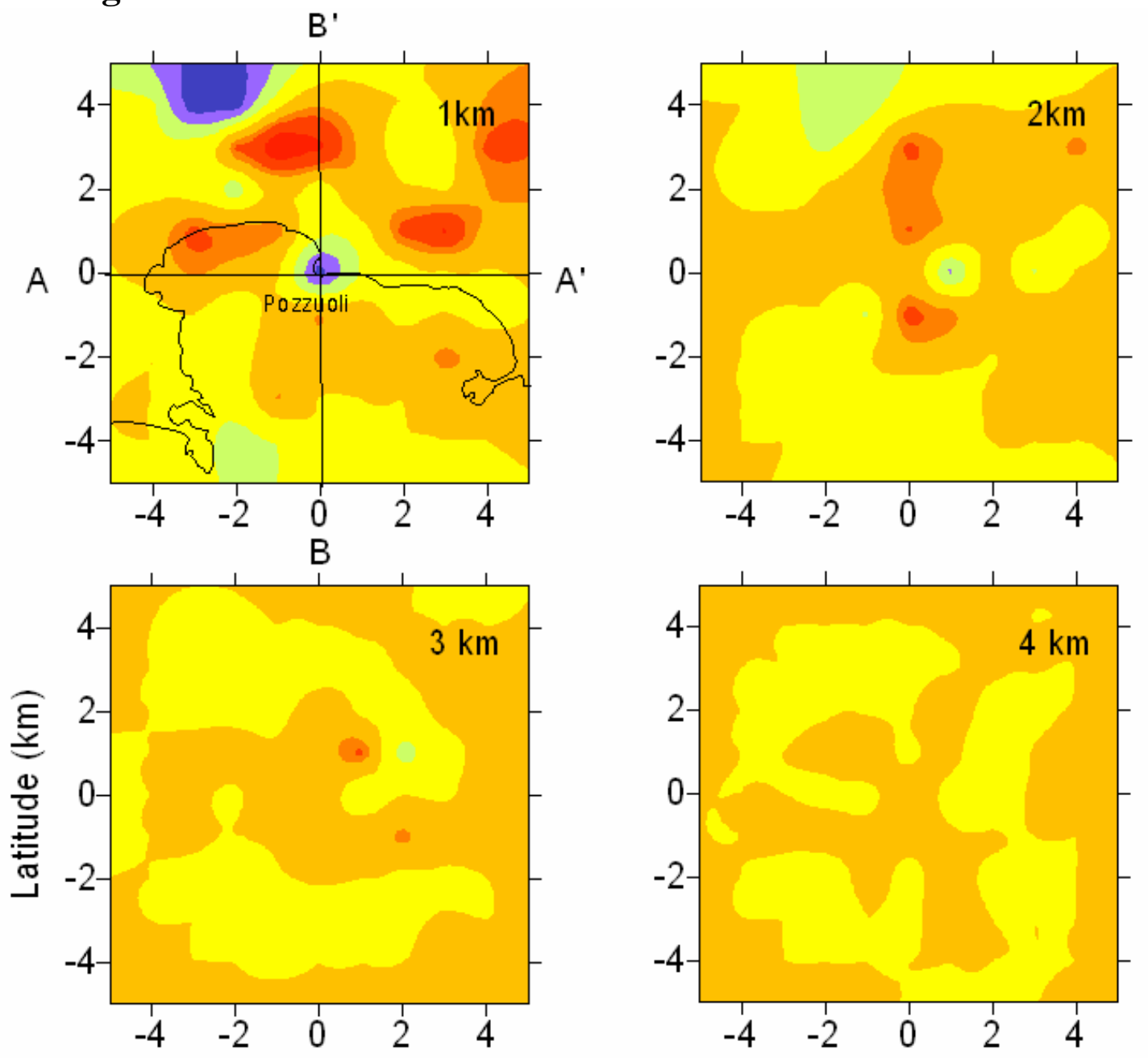

Longitude $(\mathrm{km})$

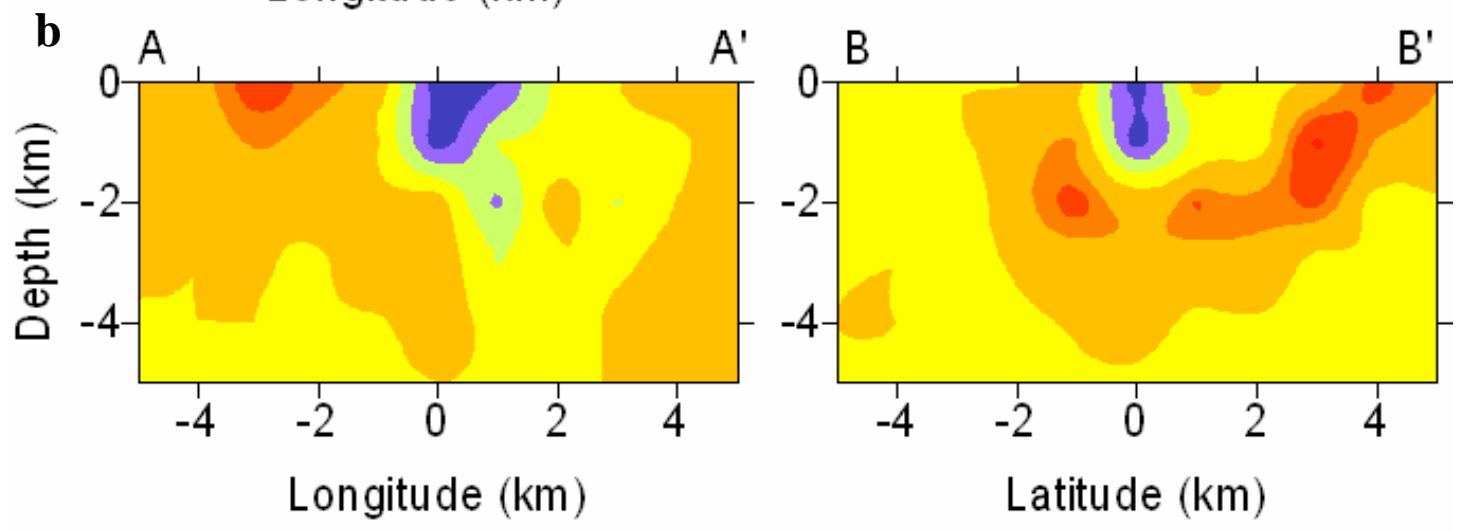

$\begin{array}{lllllllll}2.3 & 2.5 & 2.7 & 2.8 & 3 & 3.2 & 3.4 & 3.6 & 3.8\end{array}$

$\mathrm{Vp}(\mathrm{km} / \mathrm{sec})$ 
Fig. 13
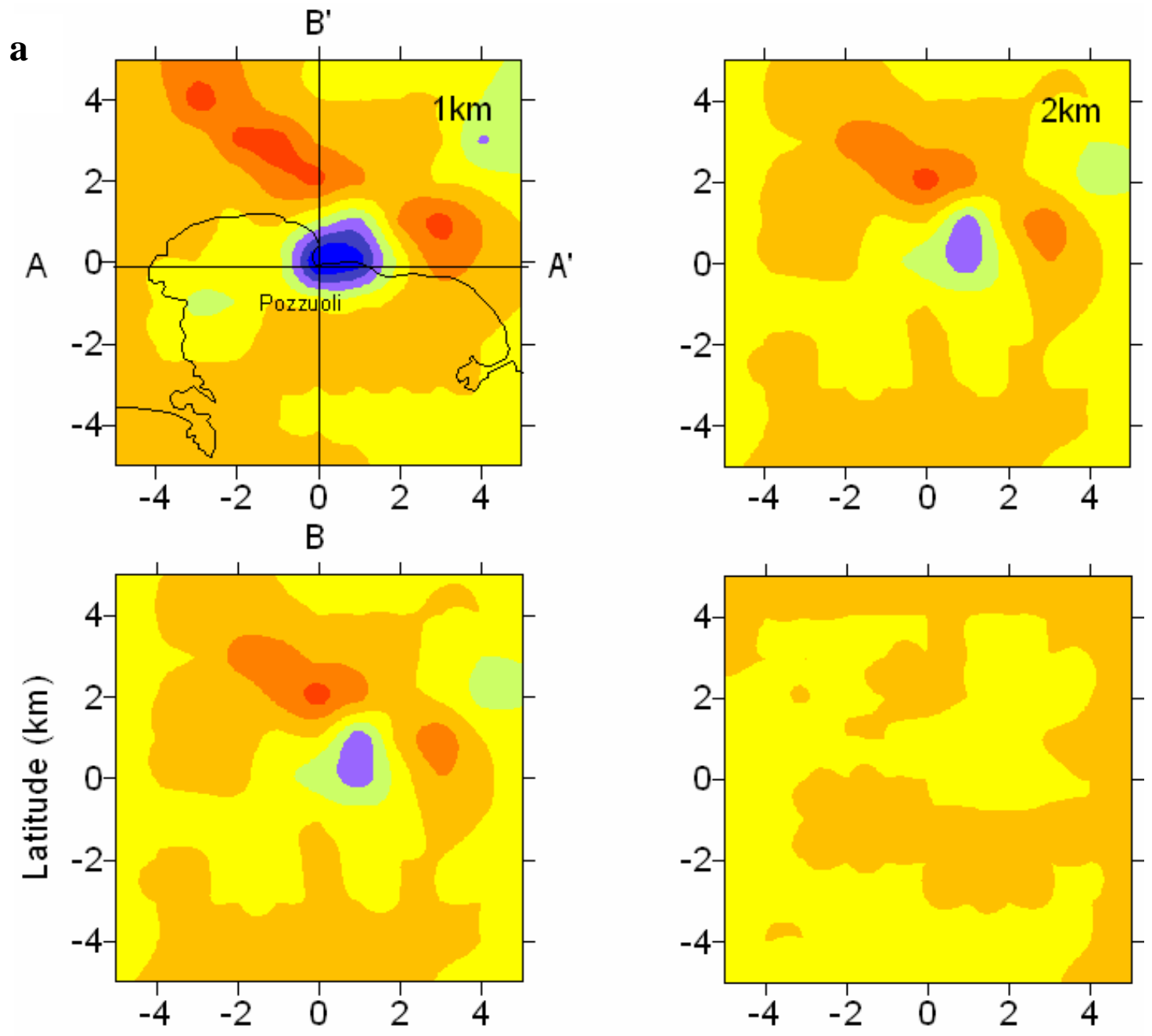

b Longitude $(\mathrm{km})$

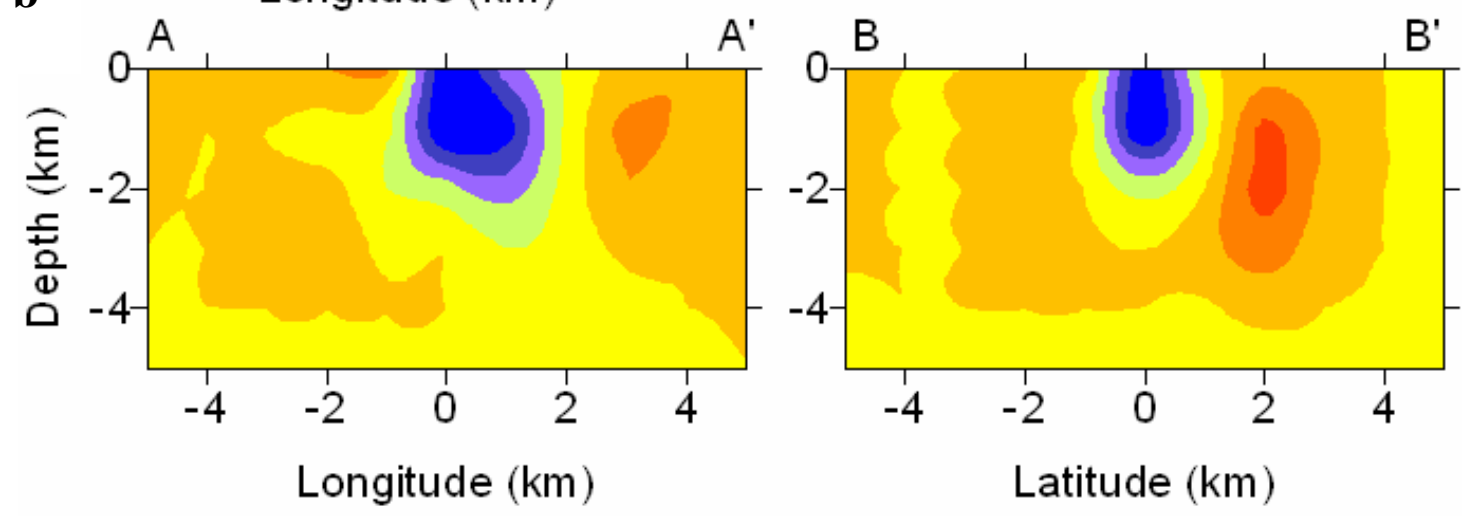

$1.61 .651 .71 .751 .81 .851 .91 .95 \quad 2$ $\mathrm{Vp} / \mathrm{Vs}$ 